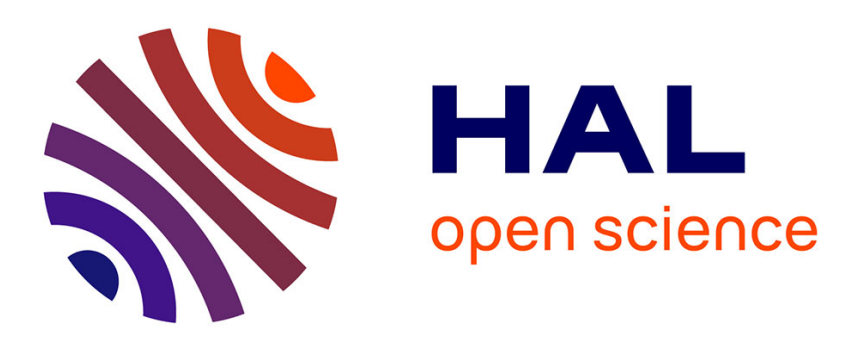

\title{
Neutron-rich In and Cd isotopes close to the doubly-magic ${ }^{132} \mathrm{Sn}$
}

\author{
A. Scherillo, J. Genevey, J.A. Pinston, A. Covello, H. Faust, A. Gargano, R. \\ Orlandi, G.S. Simpson, I. Tsekhanovich
}

\section{- To cite this version:}

A. Scherillo, J. Genevey, J.A. Pinston, A. Covello, H. Faust, et al.. Neutron-rich In and Cd isotopes close to the doubly-magic ${ }^{132} \mathrm{Sn}$. 3rd International Workshop on Nuclear Fission and FissionProduct Spectroscopy, Fission 2005, May 2005, Chateau de Cadarache, Saint Paul Lez Durance, France. pp.145-148, 10.1063/1.2137240 . in2p3-00024167

\section{HAL Id: in2p3-00024167 https://hal.in2p3.fr/in2p3-00024167}

Submitted on 26 May 2005

HAL is a multi-disciplinary open access archive for the deposit and dissemination of scientific research documents, whether they are published or not. The documents may come from teaching and research institutions in France or abroad, or from public or private research centers.
L'archive ouverte pluridisciplinaire HAL, est destinée au dépôt et à la diffusion de documents scientifiques de niveau recherche, publiés ou non, émanant des établissements d'enseignement et de recherche français ou étrangers, des laboratoires publics ou privés. 


\title{
Neutron-Rich In and Cd Isotopes Close to the Doubly-Magic ${ }^{132}$ Sn
}

\author{
A. Scherillo"s, J. Genevey", J.A. Pinston", A. Covello", H. Faust", A. \\ Gargano $^{\sharp}$, R. Orlandi ${ }^{\star}$, G.S. Simpson*, I. Tsekhanovich* \\ *Institut Laue-Langevin, B.P. 156, F-38042 Grenoble Cedex 9, France \\ ${ }^{\S}$ Institut für Kernphysik, Universität zu Köln Zülpicherstr.77, D-50937 Köln Germany. \\ "Laboratoire de Physique Subatomique et de Cosmologie, IN2P3-CNRS/Université Joseph Fourier, \\ F-38026 Grenoble Cedex, France \\ ${ }^{*}$ Dipartimento di Scienze Fisiche, Università degli studi di Napoli Federico II and INFN, Complesso \\ Universitario di Monte Sant'Angelo, via Cintia, I-80126 Napoli, Italy \\ ${ }^{\sharp}$ Department of Physics and Astronomy, The University of Manchester, \\ Brunswick Street, M13 9PL, United Kingdom
}

\begin{abstract}
Microsecond isomers in the In and Cd isotopes, in the mass range A $=123$ to 130 , were investigated at the ILL reactor, Grenoble, using the LOHENGRIN mass spectrometer, through thermalneutron induced fission reactions of Pu targets. The level schemes of the odd-mass ${ }^{123-129}$ In are reported. A shell-model study of the heaviest In and Cd nuclei was performed using a realistic interaction derived from the CD-Bonn nucleon-nucleon potential.
\end{abstract}

PACS: $21.10 . \mathrm{Tg}, 23.20 . \mathrm{Lv}, 25.85 . \mathrm{EC}, 27.60 .+\mathrm{j}$

Experimental progress is currently being made in the region around doubly-magic ${ }^{132} \mathrm{Sn}$. However, nuclear structure information is more complete for nuclei above the $\mathrm{Z}=50$ shell-closure [1] such as $\mathrm{Sb}$ and Te isotopes than for the In and Cd isotopes, which are much more difficult to produce. In the present work we searched for and studied the decay of $\mu$ s isomers in the neutron-rich mass $A=123$ to 130 nuclei with the LOHENGRIN spectrometer at the ILL reactor in Grenoble. The aim was to complete the previous data on the heavy $\mathrm{Cd}$ and In isotopes.

The low-spin levels up to $13 / 2$ in ${ }^{123-127}$ In were previously investigated from the $\beta$ decay of Cd isotopes [2,3], and, very recently, high-spin ms isomers in ${ }^{125-129}$ In were discovered [4,5]. Krautzsch et al [6], have also obtained some spectroscopic information on the ${ }^{126-128} \mathrm{Cd}$ isotopes. Preliminary reports were presented by Hellström et al $[7,8]$ on the search for $\mu$ s isomers in the heavy Cd and In isotopes at the FRS spectrometer at GSI, but no level schemes were proposed.

Our new results on odd-In isotopes have been published recently $[9,10]$. In ${ }^{127}$ In we have observed a 9(2) $\mu$ s isomer which decays by a cascade consisting of a stronglyconverted E2 transition of $47 \mathrm{keV}$, and two $\gamma$-rays of 221 and $233 \mathrm{keV}$ in coincidence one with the other (fig. 1,2). The two $\gamma$-rays were the same as those first observed by Hellström et al [7,8], and the reported value of the half-life 13(2) $\mu$ s is in rough agreement with that found in this work. The coincidence spectra presented on fig. 1 was obtained with the two new clover detectors and the new chamber. It shows the improvement of the $\gamma$-efficiency of our setup. 
The $\mathrm{Si}(\mathrm{Li})$ spectrum obtained in coincidence with any of these two lines shows the characteristic indium X-rays, and the $\mathrm{K}$ and $\mathrm{L}$ conversion electrons of the isomeric transition. The multipolarity of the transition is E2, and $\mathrm{B}(\mathrm{E} 2)=0.3 \mathrm{~W} . \mathrm{u}$. was deduced.
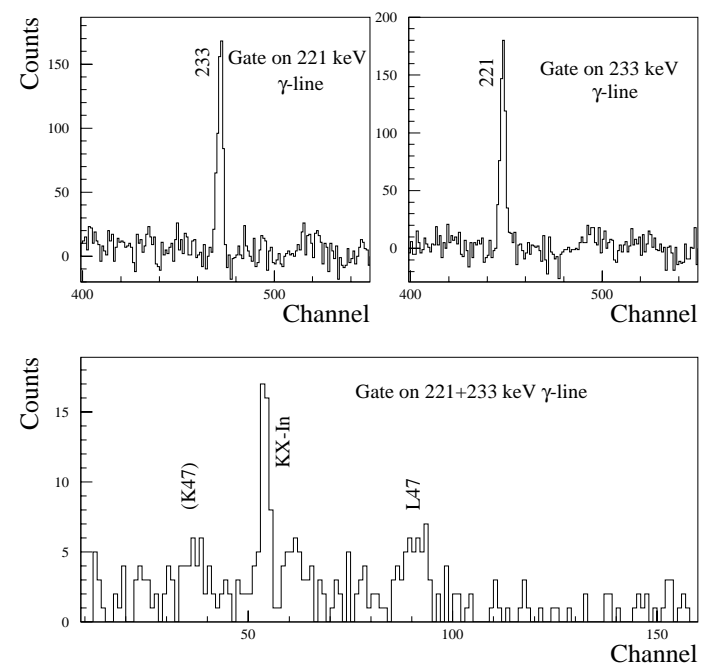

FIGURE 1. Coincidence spectra gated on the $\gamma$-ray of 233 or $221 \mathrm{keV}$ and $\mathrm{Si}(\mathrm{Li})$ spectrum obtained in coincidence with the $\gamma$-rays of 221 and $233 \mathrm{keV}$.

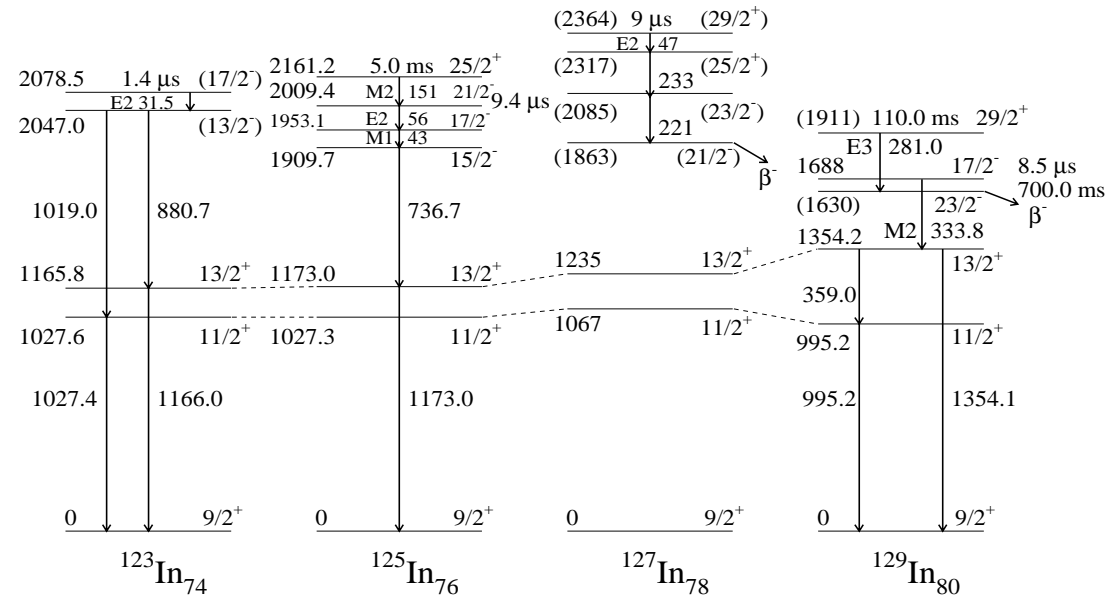

FIGURE 2. Level schemes of ${ }^{123,125,127,129}$ In. The level energies in parenthesis are deduced from $\beta$ spectra [5] have large uncertainties.

The level schemes of ${ }^{123-129}$ In shown in fig.2 are the result of the synthesis of different works: the ms isomer experiments performed at the OSIRIS mass separator [4,5], and the $\mu \mathrm{s}$ isomer experiments performed with the FRS at GSI $[7,8]$ and the LOHENGRIN spectrometer[1,9,10]. All the reported levels are in the vicinity of the yrast line, therefore the low-spin levels fed in previous works by $\beta$-decay experiments are not shown in fig. 2.

The heavy In and Cd nuclei, with neutron and proton holes inside the ${ }^{132} \mathrm{Sn}$ core, are characterized by the presence of two high-spin states, $\pi g_{9 / 2}{ }^{-1}$ and $v_{11 / 2}{ }^{-1}$ at low 
excitation energy. The very strong $p-n$ interaction in the $\left(\pi \mathrm{g}_{9 / 2}{ }^{-1} \mathrm{vh}_{11 / 2}{ }^{-1}\right)$ configuration is expected to produce very perturbed yrast line and give rise to long-lived high spin isomers.

We have performed calculations to test the ability of the shell model to describe the heavy $\mathrm{Cd}$ and In isotopes, with proton and neutron holes outside the ${ }^{132} \mathrm{Sn}$ core. In this work, a realistic effective interaction derived from the CD-Bonn nucleon-nucleon potential [11] is used. Similar calculations were performed in Ref. [12] for nuclei with proton particles and neutron holes around ${ }^{132} \mathrm{Sn}$, and in Ref. [9] for ${ }^{129} \mathrm{In}$. In both cases good agreement with the experimental data was found

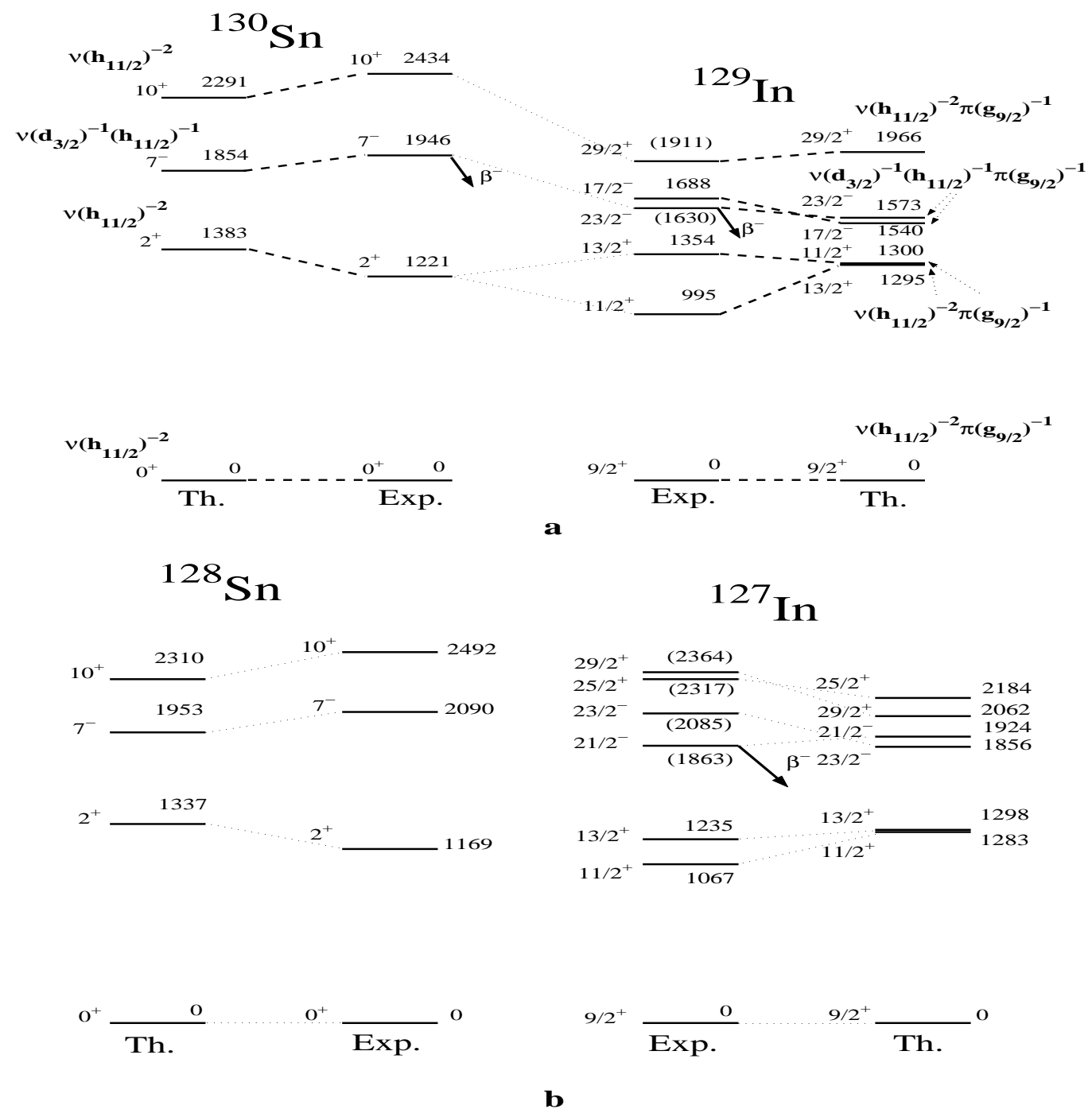

FIGURE 3. Experimental and calculated energies for ${ }^{129}$ In and ${ }^{130} \mathrm{Sn}$ (a), and for ${ }^{127} \mathrm{In}$ and ${ }^{128} \mathrm{Sn}$ (b).

In Fig. 3a experimental levels of ${ }^{129}$ In and ${ }^{130} \mathrm{Sn}$ are shown together with the calculated ones. For ${ }^{129}$ In all the experimental levels, except the $1 / 2^{-}$at $369 \mathrm{keV}$, are reported, while only some selected yrast level of ${ }^{130} \mathrm{Sn}$ are shown. The dominant configurations of all these levels are also indicated. The excitation energies of ${ }^{130} \mathrm{Sn}$ are rather well reproduced by the shell-model calculations. However, it is interesting to note that the first $2^{+}$state is overestimated by the calculation by $162 \mathrm{keV}$. This is a common feature for this state in this region and it is probably an effect of the 
truncation of space. The experimental levels of ${ }^{129}$ In are expected to result from the coupling of a $\pi \mathrm{g}_{9 / 2}{ }^{-1}$ hole with the reported two neutron hole states of ${ }^{130} \mathrm{Sn}$.

The comparison of the experimental levels in Fig. 3b shows that the $29 / 2^{+}$and $23 / 2^{-}$in ${ }^{127}$ In are closer to the $10^{+}$and $7^{-}$in ${ }^{128} \mathrm{Sn}$ respectively, than in Fig. 3a. This effect could be explained by a decrease of $p-n$ interaction from ${ }^{129}$ In to ${ }^{127} \mathrm{In}$. Another feature, possibly related to the effects of the $p-n$ interaction is the inversion of the $29 / 2^{+}$and $25 / 2^{+}$and $23 / 2^{-}$and $21 / 2^{-}$levels, respectively, in the calculated spectrum of ${ }^{127}$ In.

In the vicinity of the two closed shells of ${ }^{132} \mathrm{Sn}$ the $\mu$ s isomers are very abundant and disappear rapidly far from them [1]. However, below $\mathrm{Z}=50$ they disappear suddenly for the $\mathrm{Cd}$ isotopes, no isomers having been identified up to now in the even-mass ones. The calculations for ${ }^{126,128} \mathrm{Cd}$ predict short half-lives ( $\left.\sim 10 \mathrm{~ns}\right)$ for the $8^{+}$states, which could explain why they have not been observed in the present work. In ${ }^{130} \mathrm{Cd}$ no excited levels are experimentally known up to now. The shell model calculations predict an isomer $8^{+}$of $0.6 \mu \mathrm{s}$, very close to the LOHENGRIN detection limit. The low yield estimate for this element make a measurement very difficult.
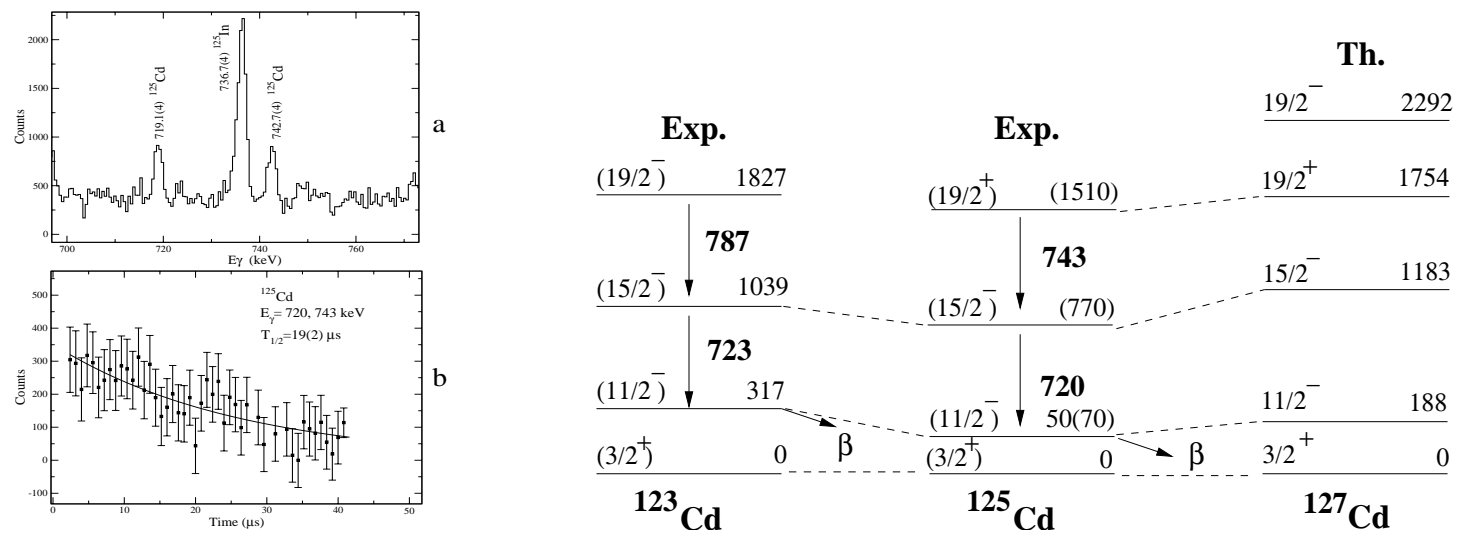

FIGURE 4. $\gamma$-spectrum obtained in delayed coincidence with mass $A=125$ (a). Time spectrum of ${ }^{125} \mathrm{Cd}(\mathrm{b})$. Experimental levels of ${ }^{125} \mathrm{Cd}$ in comparison with ${ }^{123} \mathrm{Cd}$ and a theoretical calculation of ${ }^{127} \mathrm{Cd}$.

In the odd-nuclei, only the isomer of ${ }^{125} \mathrm{Cd}$, which decays by two $\gamma$-lines of the same intensity, as seen in Fig. 4, is known. Its half-life is 19(2) $\mu \mathrm{s}$, in rough agreement with the value reported previously $[7,8]$. A tentative level scheme is proposed by analogy with its neighbour ${ }^{123} \mathrm{Cd}$ and a shell model calculation on ${ }^{127} \mathrm{Cd}$.

\section{REFERENCES}

1. Pinston, J.A and Genevey, J., J. Phys. G 30, R57 (2004)

2. Hoff, P.,et al., Nucl. Phys. A459,35 1986).

3. Huck, H., et al., Phys. Rev. C39, 997 (1989).

4. Fogelberg, B., et al., Proc. 2nd Intern. Workshop on Fission and Fission-Product Spectroscopy (Seyssins, France) (AIP Conf. Proc 447) Ed. by G. Fioni, H. Faust, S. Oberstedt, F. Hambsch, p. 191

5. Gausemel, H., et al., Phys. Rev. C69, 054307 (2004).

6. Krauzsch, T., et al., Eur. Phys. J. A 9, 201(2000).

7. Hellström, M., et al., Proc. 3rd Conf. on Fission and Properties of Neutron-Rich Nuclei (Sanibel Island,FL) 2002, Ed. by J. Hamilton , A. Ramayya, H. Carter (Singapore: World Scientific), p.22.

8. Hellström, M., et al., Proc. of Intern. Workshop XXXI on Gross Properties of Nuclei and Nuclear Excitations (Hirscheg, Austria) Ed. by H. Feldmeier, GSI 2003, p.72.

9. Genevey, J., et al., Phys. Rev. C67, 054312 (2003).

10. Scherillo, A., et al., Phys. Rev. C70, 054318 (2004), and PhD Thesis, Cologne, Germany 2005.

11. Machleidt, R., et al., Phys. Rev. C63, 024001 (2001)

12. Corragio, L., et al., Phys. Rev. C66, 064311 (2002). 
